of the whole reckoning system refers to a day. which in this almost perpetual calendar is a 4 Ahau katun, which begins with the eighth day of the score called Kumku. This has therefore been called the normal or zero date, from which all the monumental dates reckon in days, scores of days, years, scores of years, and cycles. Astronomers do not seem to have taken up the question whether this zero-date, which lies somewhere near 3000 B.c., may possibly refer to some remarkable planetary configuration. It may, however, be altogether fictitious. Very little is known about their cosmogony, and it is not known why they should have considered themselves in the ninth cycle of their world's history when they constructed the Quirigua and Copan monuments. This mode of reckoning was still used at the Spanish conquest, but as they had not invented a leap-year correction they occasionally shifted their new year's day to make the religious feasts tally with the actual seasons. But since it is not known when such shifts were made, and since the various nations did not interpolate alike, none of the numerous dates can be determined.

Most of this American archæology is still in the descriptive stage. For instance, the less there is known about the reason why the chief deity, or hero, Kukulcan or Quetzacoatl, the Great Plumed Serpent, is thus represented, the more minutely he is described and figured wherever a fragment of him is found. We can see that it is a snake. But the answer to the pertinent question: Why a serpent? That there is no particular reason except that "the body of a snake combines readily in art with certain characteristic parts of other animals," that it lends itself especially well to design and ornamentation, is rather disappointing.

H. G.

\section{BIRDS AND WEATHER.1}

THE difficult question of the influence of meteorological conditions on the phenomena of bird migration has fortunately been very thoroughly studied as regards the British area, but we are none the less glad to welcome the recent labours of Dr. Defant on this subject. Dr. Defant as a meteorologist has submitted to a critical examination the data collected some years ago regarding the spring arrival in Austria of some thirty species of birds. He has selected four species for special treatment, and the data cover a period of seven seasons (1897-1903). The published weather reports have supplied all the necessary meteorological data for the corresponding periods.

At the outset of his paper Dr. Defant points out that, while all meteorological factors must be taken into account, the relation of all other conditions to that of atmospheric pressure renders possible a concentrated attention on the latter. A comparison of the ornithological data with the

1 "Der Einfluss des Wetters auf die Ankunftszeiten der Zugvögel im Frühling." By Dr. A. Defant, Vienna. Reprinted from Sclizualbe, new series, vol, iii., r9r3, pp. $135-56$, and charts.

$$
\text { NO. 233I, VOL. 93] }
$$

temperature records gave a purely negative result, no direct relation being discoverable. Dr. Defant also rightly insists on the importance of considering the weather of the whole of southern Europe, the conditions prevailing in the actual area of arrival being obviously less important than those in the regions immediately to the south through which the migrants must pass.

The spring immigration of the starling and the lark are treated together, these species showing a detailed similarity in this aspect of their seasonal movements. Tables are given showing that there is an annual variation both in the earliest date of arrival and in the duration of the influx. The period of heavy immigration usually lasts about eight days and the average date of maximum arrival for the seven years was February 23, while the average dates for particular years varied from February I 2 to March 3 .

With the partial exception of one year out of the seven it was found that the periods of maximum immigration coincided with periods of low atmospheric pressure in the west and north-west of Europe and higher pressure in the south, southeast, or east. These conditions give southerly or south-easterly winds in Austria and the countries immediately to the south, and usually rising temperatures. The immigration was all the greater when these favourable conditions had been immediately preceded by a prevalence of high pressure in the north and north-west (or north-east) and low pressure in the east or south-east; such conditions usually entail low temperatures and northerly or north-westerly winds.

Dr. Defant then considers the average daily pressure for the three regions into which he divides southern Europe. These are $\mathrm{A}=$ western Asia Minor, the Balkan Peninsula, the Adriatic Sea, and southern Italy ; $B=$ the remaining greater part of Italy, the western Mediterranean and northern Africa; and $\mathrm{C}=$ Spain and Portugal. The last-named region is soon shown to be irrelevant, and Dr. Defant's second conclusion results from a comparison between $\mathrm{A}$ and $\mathrm{B}$. He finds that strong immigration in Austria occurred when the pressure in these regions was relatively higher than on the days immediately before and after and when the pressure in A was higher than in B. The east to west pressure gradient thus formed when coupled with the effect of the earth's rotation produces the south-easterly winds characteristic of the type of weather already described as favourable to migration.

The cuckoo and the house martin are then treated in like manner (not jointly as in the previous case, but simultaneously to economise space in tables and graphs). The same two conclusions are arrived at for these immigrations occurring much later in the season than that of the starling and the lark. A second type of weather was also found favourable in the case of the cuckoo, namely, extended high pressure over the whole of central and southern Europe, usually with weak easterly or north-easterly winds. In seasons 
in which the strongest immigration occurred under such conditions the period of the chief movement was protracted to about nineteen (instead of about nine) days.

Dr. Defant has clearly proved that a certain type of weather is peculiarly favourable for the spring immigration of Austrian birds. $\mathrm{He}$ is to be congratulated on his clear and well reasoned treatment of very unwieldy data and on having made a valuable contribution to a difficult subject.

His further speculations are, however, open to serious criticism. He believes that the important factor in this type of weather is the wind and that birds prefer to fly with it behind them. His reasons as to why birds should do so seem to us to be wholly beside the point, and as the much more comprehensive results already obtained in this country are entirely opposed to Dr. Defant's theory, we cannot accept it, however temptingly obvious it may seem, on such very slender grounds.

The alternative theory is that "the winds and the performance, or non-performance, of the migratory movements are the effects of a common cause-namely, the particular type of weather prevailing at the time, which may be favourable or unfavourable for the flight of birds. . .." (Eagle Clarke, "Studies in Bird Migration," I912, p. I73).

In the British area there are certain types of weather favourable respectively for migration between the British Isles and northern Europe, between the British Isles and Iceland, and between the British Isles and south-western Europe. The winds accompanying these types of weather may or may not be in the same direction as the movements concerned. Furthermore, the same types of weather favour these movements both in autumn and in spring, the direction of flight being reversed, while the prevailing winds remain the same.

In Dr. Defant's simpler case it so happens that the favourable type of weather he has discovered produces a wind in the same direction as that of immigration from the Balkan Peninsula (his region " $A$ ") to Austria ; but the immigration from the south-west ("B") probably forms a large part of the movements which were the subject of investigation. It is unfortunate that only the spring migrations have been dealt with. Should the same type of weather with its accompanying winds prove to be favourable to the autumn emigration (as in the case of the British movements), Dr. Defant's theory would be quite untenable.

In the meantime, Dr. Defant's selection of wind as the important factor is purely speculative, and his view entails an entirely different relation between birds and weather in Austria from that existing in the British Isles. While rejecting his theory of the importance of wind as unproven and improbable, we feel grateful for the new facts which he has added to our knowledge of bird migration by his most laborious and thorough research.

A. Landsborough Thomson.

\section{METROLOGICAL RESEARCHES.1}

r THE volumes referred to below contain particulars of recent metrological researches made at the international bureau of weights and measures. As the result of a long series of investigations on the length of invar wires used for geodetical measurements, it has been found that wires made of metal taken from the same tapping or ladle and treated in the same manner have practically the same coefficients of expansion; the differences from the mean lying within $\pm 0^{\circ} 03 \times 10^{-6}$. If the same coefficient of expansion were adopted for all such wires it would need a difference of temperature of $30^{\circ} \mathrm{C}$. to introduce an error of one part in a million. There is now no difficulty in procuring invar wires having a coefficient of expansion as small as $0^{\circ} \mathrm{I} \times 1 \mathrm{O}^{-6}$.

At the fifth general conference on weights and measures held in Paris in October last, a resolution was passed to the effect that in view of the fact that the force of gravity is not precisely the same at sea-level for all places having the same latitude, it was undesirable that the value adopted for the normal force of gravity (viz., 980.665 cm. sec. ${ }^{-2}$ ) should continue to be defined as that corresponding to a particular latitude $\left(45^{\circ}\right)$. In the reduction of observations the theoretical factor given by Clairaut's formula in the amended form now usually adopted should no longer be $\in \mathrm{m}$ ployed, but merely the numerical ratio of the normal force of gravity to that at the place of observation, the latter being determined directly if possible.

The normal scale of temperature hitherto adopted at the international bureau of weights and measures has been that of hydroyen at constant volume. The fifth general conference resolved that the absolute thermodynamic scale shall be substituted for the hydrogen scale as soon as the table of reduction from one scale to the other has been determined with sufficisnt certainty. It was also recommended that a number of thermometric fixed points be ascertained with as great accuracy as possible, in order to facilitate the calibration of thermometers. A meeting of the principals of the various national laboratories is to be arranged at Sèvres for the purpose of deciding what these fixed points shall be and how they are to be determined, as well as to promote their general recognition.

The question of the determination of the length of the metre in terms of wave-lengths of light was considered at the fourth general conference. It was decided that investigation on this subject had not then reached the stage for the conference to adopt any particular number of wave-lengths as representing the metre. Further researches made by physicists will be carefully studied at the international bureau with the view of obtaining in the course of time a fundamental

1 Comite internationale des poids et mesures. Procès-verbaux des stances' Deuxième série, tome vii., session de 19r3. Pp. v+140. (Paris: Gautbier. Villars, 1913.)

Travaux et Mémoires du bureau international des poids et mesures. Tome xv. (Paris: Gauthier-Villars, 19r3.) NO. 233I, VOL. 93] 